\title{
Maturity Changes in Norwegian Spring-spawning Herring Before, During, and After a Major Population Collapse
}

Georg H. Engelhard (georg.engelhard@imr.no)

Mikko Heino (mikko.heino@imr.no)

\section{Approved by}

Ulf Dieckmann

Project Leader, ADN

December 2003 Institute, its National Member Organizations, or other organizations supporting the work. 


\section{Contents}

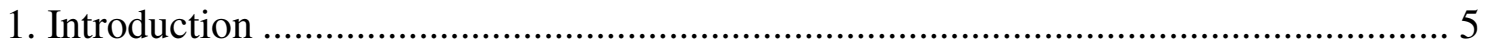

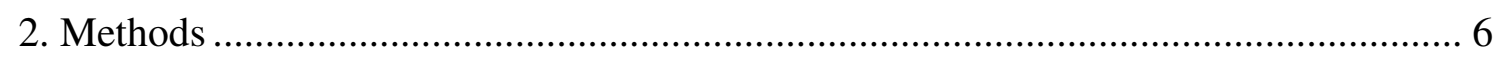

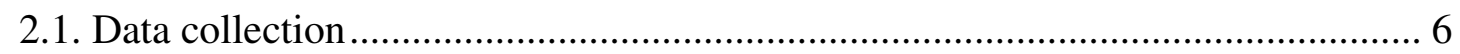

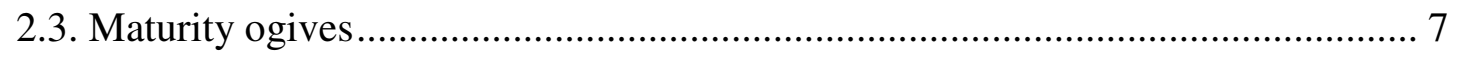

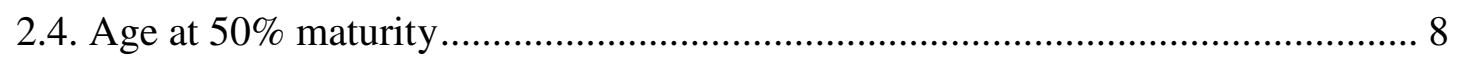

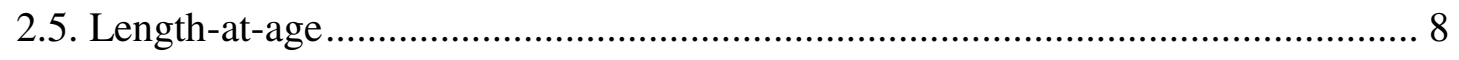

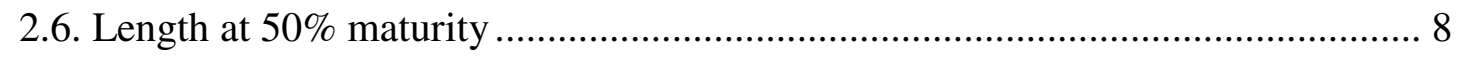

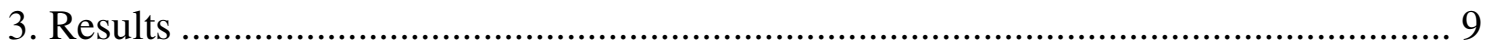

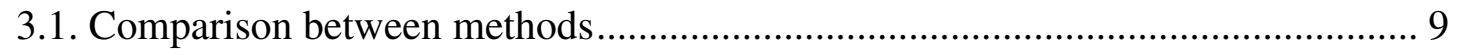

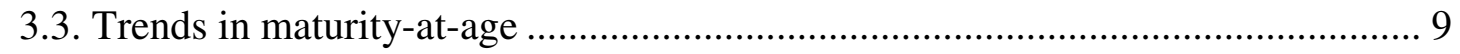

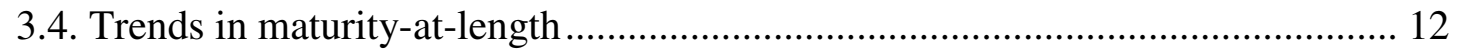

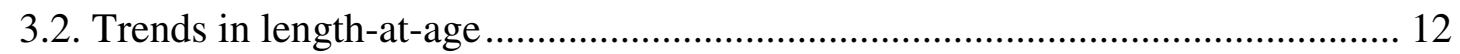

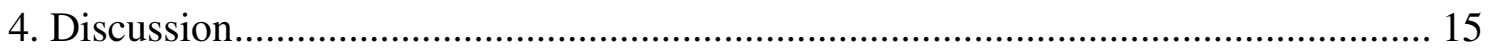

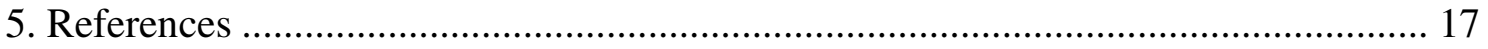




\begin{abstract}
The Norwegian spring-spawning herring (Clupea harengus) population collapsed to the state of commercial extinction in the late 1960s; the stock remained at extremely low levels for over two decades, but has recovered fully since the 1980s. It is known that the collapse coincided with strong changes in maturation characteristics. However, the long-term patterns of maturation in this stock have remained largely undescribed. We applied discriminant and neural network analysis to historical scale data to predict age at maturation for individual herring of the year-classes 1930-1992. Based on these data, this paper (1) presents new, revised maturity ogives for these year-classes with a temporal resolution of one year, and (2) describes the long-term variability in age at $50 \%$ maturity, length at 50\% maturity, and length-at-age. This new information shows that during the period of low stock abundance, age at $50 \%$ maturity was considerably reduced and length at 50\% maturity moderately increased as compared to the situation both before and after the collapse. These variations coincided with changes in length-atage, suggesting that the maturity changes to a large extent reflect variations in body growth related with stock abundance.
\end{abstract}




\title{
About the Authors
}

\author{
Georg H. Engelhard \\ Institute of Marine Research \\ P.O. Box 1870 Nordnes \\ N-5817 Bergen \\ Norway \\ and \\ Adaptive Dynamics Network \\ International Institute for Applied Systems Analysis \\ Schlossplatz 1 \\ A-2361 Laxenburg \\ Austria \\ Mikko Heino \\ Institute of Marine Research \\ P.O. Box 1870 Nordnes \\ N-5817 Bergen \\ Norway \\ and \\ Adaptive Dynamics Network \\ International Institute for Applied Systems Analysis \\ Schlossplatz 1 \\ A-2361 Laxenburg \\ Austria
}

\section{Acknowledgments}

We are grateful to Ulf Dieckmann, Olav Rune Godø, Ingolf Røttingen, Aril Slotte, Reidar Toresen, and our anonymous referee for valuable suggestions and discussions contributing to this paper. Oddvar Dahl, Annlaug Haugsdal, and Jan Henrik Nilsen provided GHE extensive information on the analysis of herring scales. The study was supported by the European Research Training Network ModLife (Modern Life-History Theory and its Application to the Management of Natural Resources), funded through the Human Potential Programme of the European Commission (Contract Number HPRN-CT-2000-00051) and by the Academy of Finland (Project 45928). 


\title{
Maturity Changes in Norwegian Spring-spawning Herring Before, During, and After a Major Population Collapse
}

\author{
Georg H. Engelhard \\ Mikko Heino
}

\section{Introduction}

Norwegian spring-spawning herring (Clupea harengus) is the world's largest herring stock, distributed in the Norwegian and Barents Seas. Over the past centuries, this commercially highly valuable stock showed substantial fluctuations in abundance (e.g. Hjort, 1914; Devold, 1963; Toresen and Østvedt, 2000). The most dramatic of these occurred when, starting from a spawning stock biomass of 10-16 million tonnes in the 1940s, the population declined throughout the 1950s and 1960s, until it collapsed to the state of commercial extinction in the late 1960s. A historic minimum of 2000 tonnes occurred in 1972, and the spawning stock remained at extremely low levels throughout the 1970s. With the remarkably strong 1983 year-class, the biomass increased rapidly. At present the stock is considered fully recovered, with a spawning stock biomass of 5-10 million tonnes in recent years (Toresen and Østvedt, 2000). It is now well accepted that climatic factors have a large impact on the abundance fluctuations (Toresen and Østvedt, 2000; cf. Corten, 2001). However, the causes of the collapse in the 1960s have been, and still are a topic of debate. Probably a combination of unfavourable climatic conditions and overfishing of both adult and juvenile herring contributed to the decline; however, the relative importance of these factors is unknown (Dragesund and Ulltang, 1978; Hamre, 1990; Toresen, 2002).

Both age and size at maturation are tightly linked to lifetime fecundity of individuals (Stearns, 1992; Bernardo, 1993), and therefore to stock productivity. Assessing these parameters in commercially exploited fish stocks is therefore of high importance (Marshall et al., 1998; Murawski et al., 2001). Marked changes in these life-history characteristics have occurred in many fish stocks; for example, age and size at maturation decreased considerably over the past decades in North Sea plaice (Pleuronectes platessa: Rijnsdorp, 1993) and several stocks of Atlantic cod (Gadus morhua: Jørgensen 1990; Trippel, 1995; Godø, 2000; Barot et al., 2002).

A clear decrease in age at maturation was also observed in the Norwegian springspawning herring stock, after its abundance was severely reduced in the late 1960s (Toresen, 1990a, b). At least two, non-exclusive hypotheses may account for these changes. First, earlier maturation might be a phenotypically plastic response of the fish to changes in their environment, affecting the conditions for growth and hence maturation, which is typically size-dependent. In particular, a harvest-induced reduction in stock biomass would likely relax intraspecific competition, leading to compensatory growth and earlier maturation. Faster growth in the years following collapse has indeed been reported for Norwegian springspawning herring (Toresen, 1990a). Second, earlier maturation might be an evolutionary 
response to the selective effects of fishing. Fishing mortality rates in this stock have been high in the decades before and after collapse, in some years even exceeding $F=2 \mathrm{yr}^{-1}$ (Toresen and Østvedt, 2000). It is known that high fishing mortality may select for early maturation (Law and Grey 1989; Browman, 2000; Law, 2000; Heino and Godø, 2002), as has been shown for Northeast Arctic cod (Heino et al., 2002) and North Sea plaice (Grift et al., 2003).

It is known, in general terms, that changes in maturity have occurred in the Norwegian spring-spawning herring stock (Toresen, 1990a, b). However, due to logistic restrictions (Barros and Holst, 1995) the long-term patterns of maturity in this stock have remained largely undescribed, and are particularly poorly known for the three most recent decades. This paper aims at filling this gap. We used discriminant analysis and artificial neural networks to predict age at maturation from routine scale measurements (Engelhard et al., 2003). We applied these methods to historical data on herring scales collected since 1935. Based on these data, the present paper, first, describes the long-term variability in maturity for the year-classes 1930-1992. Second, it examines if during the period of stock collapse represented by the long row of weak year-classes from 1967 to 1982 - the maturation characteristics were different from those in the pre- and post-collapse periods.

\section{Methods}

\subsection{Data collection}

The study is based on mature individuals of Norwegian spring-spawning herring, sampled by the Insititute of Marine Research (Bergen) on the spawning grounds during January-March in 1935-2000. Samples of 100-200 herring were collected from drift-net, beach-seine, purseseine, and trawl catches, caught by either commercial or research vessels. These samples are considered to be representative of the spawning stock (e.g. Toresen, 1990a; Holst, 1996); this was also supported by preliminary comparisons of observed and back-calculated mean lengths-at-age for the examined year-classes, that revealed only minor differences (unpublished).

For each fish, standard measurements were taken including body mass, length, sex, and maturity stage. When available, up to four scales were collected from the skin just behind the operculum, along the lateral body line, and conserved for later analysis. By microscopic examination of the scales, the age was determined based on the total number of growth layers.

In addition, for the majority of fish collected between 1935 and 1973, experienced scale readers determined the age at maturation based on observations of each of the growth layers in the scales (Lea, 1928, 1929; Runnström, 1936). This implied the distinction between (1) 'coastal' rings corresponding to the juvenile stage (rather narrow to very wide summer zones divided by either diffuse or sharp winter rings), (2) 'oceanic' rings corresponding with the late immature stage when the animals live in the Norwegian Sea (wide summer zones divided by diffuse winter rings), and (3) 'spawning' rings corresponding to years during which the herring spawned (narrow to very narrow outer summer zones divided by sharp winter rings).

However, for practical reasons, this direct observation of age at maturation was discontinued in 1974, and a new method allowing growth studies was initiated. This new method (described by Barros and Holst, 1995) involves the measurement of the total radius of the scale and of the radius of each annual growth layer (up to the 9th layer) along a line 
running from the focus to the edge of the scale, by means of a stereomicroscope fitted with an ocular micrometer. All scales collected since 1974 have been measured in this way; in addition, a substantial number of the old scales collected between 1935 and 1973 have recently been re-examined, and the growth layers measured exactly according to the new method.

\subsection{Predicting age at maturation from scale measurements}

Direct observations of age at maturation by scale readers were, as mentioned above, available only for years before 1974, almost confined to the pre-collapse period. The aim of this paper was, however, to examine maturity over the entire time-series before, during, and after stock collapse. We used two methods to predict age at maturation from scale growth layer data available for the entire study period; these methods are described and evaluated elsewhere (Engelhard et al., 2003). These were discriminant analysis (DA), a conventional statistical procedure; and the relatively new methodology of artificial neural networks $(\mathrm{NN})$, trained by back-propagation (Rumelhart et al., 1986). The prediction parameters in both methods were established based on the historical collection of scales where both growth layer measurements and directly observed age at maturation were available $(n=45386$ individuals, sampled between 1935 and 1973). The two classification procedures were then applied to predict age at maturation for all individuals where scale growth layers have been measured (i.e. the complete time series from 1935 to $2000 ; n=116479$ individuals). Age at maturation, which may vary from 3 to 9 years in Norwegian spring-spawning herring, was predicted at the exact, correct value (as observed by scale readers) in $68.0 \%$ and $66.6 \%$ of cases using DA or NN, respectively. Prediction errors were more than 1 year in only 5.2\% of cases (DA) or $2.9 \%$ of cases $(\mathrm{NN})$. Moreover, prediction errors were highly symmetric around the observed values for age at maturation such that the resulting bias was negligible: age at maturation was marginally underestimated using DA (1.1\% of mean age at maturation) or marginally overestimated using $\mathrm{NN}(0.2 \%$ of mean age at maturation).

\subsection{Maturity ogives}

Maturity ogives, describing the proportions of individuals mature at a given age or size, were derived based on the entire sample of herring where age at maturation had been predicted from scale measurements using either DA or NN. Again, two alternative methods were used, on the ground that these are expected to be subject to biases in opposite directions (see below), providing lower and upper estimates of the "true" ogives.

First, we applied Gulland's (1964) method, which is based on the relative abundances of recruit spawners and repeat spawners of given ages in the population (Gulland, 1964; Jørgensen, 1990). The method can thus be used with data only on mature fish. In Gulland's method, an iterative estimation procedure is started in the year during which the last fish of a year-class considered have reached maturity, i.e. when no immature fish are left (which is usually at the age of 9 in the study population). The immature part of that year-class in the previous year therefore consisted of fish that would all mature one year later, and is thus equal to the proportion of recruit spawners among the combined sample of recruit and repeat spawners one year later. Going backwards in time, the proportions of immature fish can thus be calculated for all previous ages relevant for maturation (ages of 3 to 8 years for most yearclasses of Norwegian spring-spawning herring). One important assumption in Gulland's method is that annual survival is equal for immature and mature fish of a given age. 
However, it is likely that this assumption was violated in the study population, since the majority of Norwegian spring-spawning herring fisheries has traditionally targeted the spawning (adult) stock. Higher mortality in mature when compared to immature herring would result in under-representation of early-maturing individuals among repeat spawners at higher ages, and therefore, in modest underestimation of maturity for low ages.

Second, we used a "direct" method to derive the proportions mature-at-age. In this method, each sampled individual contributes an observation to the data at the age of capture and during all earlier years of its life. Its maturity status is known from its age at maturation. This method assumes that individuals maturing at either early or late ages have equal probabilities of being represented in the data. However, as the sampling typically occurred at the spawning areas, early-maturing individuals were probably more likely to be represented in our sample than late-maturing fish, and therefore might be over-represented. Such a sampling bias would result in modest overestimation of maturity at early ages.

\subsection{Age at $50 \%$ maturity}

Based on the maturity ogives computed according to the four methods as decribed above, the age at 50\% maturity (A50) was computed using logistic regressions of maturity stage with age, for each of the considered year-classes (or year) separately.

To allow a comparison with previously published information on maturity-at-age, A50 values were moreover computed (using similar methods) based on maturity-at-age data as reported by the Northern Pelagic and Blue Whiting Fisheries Working Group (ICES, 2002; see also Toresen and Østvedt, 2000).

\subsection{Length-at-age}

Since maturation in herring is size-dependent (e.g. Toresen, 1990a), an examination of trends in length-at-age was considered necessary for the interpretation of any possible trends in maturity. As the data only included mature herring individuals, length frequency distributions including both mature and immature individuals at the ages 1 through 6 were reconstructed by back-calculations. These were based on length at catch $\left(L_{c}\right)$, total scale radius $\left(S_{c}\right)$, and the radius of the scale at age $i\left(S_{i}\right)$. We used the following formula to back-calculate length $L_{i}$ at the earlier age $i$ (scale-proportional length back-calculation, as recommended by Francis, 1990; modified from Hile, 1941):

$$
L_{i}=-r+\left(L_{c}+r\right) S_{i} / S_{c}
$$

where $r=a / b$, with $a$ and $b$ being the intercept and regression coefficient, respectively, of the linear regression of total scale radius on body length $(a=-0.949 \mathrm{~mm}, b=0.209)$.

\subsection{Length at $50 \%$ maturity}

Length frequency distributions were computed separately for immature and mature fish at ages 3 through 9. Length-at-age of individual fish was estimated by scale-proportional length back-calculations (see equation 1). By means of logistic regressions of maturity stage with length, the length at 50\% maturity (L50) was then estimated for each of the considered yearclasses separately.

The statistical analyses were carried out using the SPSS 10.0.7 package (SPSS Inc., 19891999). 


\section{Results}

Maturity ogives and lengths and ages at $50 \%$ maturity could be computed for 54 year-classes (1930-1955, 1959-1962, 1964, 1969-1970, and 1972-1992) with sufficient sample sizes. The sample sizes for these year-classes averaged 2009 individuals (median 973, range 63 to 14635 individuals). Sample sizes for the remaining nine year-classes (1956-1958, 1963, 1965-1968, and 1970) were either very low, or limited to very few ages (average 69, median 40 , range 12 to 210 individuals). These year-classes were omitted from all further analyses, except for those on mean length-at-age, where the smaller sample sizes were considered still sufficient.

\subsection{Comparison between methods}

The use of the two discrimination methods (DA and NN) to predict age at maturation from scale measurements, resulted in similar estimations of maturity, when compared to those based on age at maturation observed by scale readers (the latter data being available only for years before 1973). The values of age at 50\% maturity (A50) based on observed age at maturation, were most strongly correlated with those based on DA as discrimination method $(r=0.985$ in combination with Gulland's method, Fig. $1 a$ ), but only marginally less strongly with those based on NN ( $r=0.976$, Fig. $1 b)$. The use of DA or NN did not result in under- or over-estimation of maturity-at-age in year-classes (paired $t$-test comparing A50 values based on observed and predicted age at maturation: DA, $t=1.66, P=0.108$; NN, $t=0.64, P=$ 0.528). Given the very similar results obtained by DA and $\mathrm{NN}$, we will restrict the description of temporal trends in maturation characteristics to those obtained by DA as discrimination method.

The use of either Gulland's (1964) or the "direct" method (see Methods section) did result in somewhat larger differences in the estimated maturity-at-age (Figs. 1c,d). The estimations of A50 were significantly higher if Gulland's method was used in comparison to the values computed using the direct method (paired $t$-test comparing A50 values based on Gulland's and direct method: in combination with DA, $t=7.96, P<0.0001$; in combination with $\mathrm{NN}, t$ $=8.21, P<0.0001)$. For the lower maturation ages in particular ( 3 and 4 years), Gulland's method generally indicated smaller proportions of mature individuals than the direct method did (compare Fig. $2 a$ with Fig. $2 b$ ), while for the higher maturation ages (5 to 9 years) there was high similarity in the proportions of mature fish as computed using these two methods.

\subsection{Trends in maturity-at-age}

The maturity ogives, as computed using Gulland's and the direct method, showed the same long-term patterns, apart from the differences at ages 3-4 outlined above (Figs. 2a,b). For year-classes representing the 1930s to early 1960s, maturation occurred at high ages, with particularly high ages in year-classes of the mid-1930s. The majority of fish $(>75 \%)$ did not recruit to the spawning stock before reaching the age of 5 or 6 , or in mid-1930s, even age of 7. By contrast, in the period of collapse, characterised by the series of weak year-classes 1967-1982, maturation occurred at considerably earlier ages, and the majority of fish $(>75 \%)$ had already recruited to the spawning stock by the age of 4 . While previously only very few fish matured already at the age of 3, maturation at this early age was relatively common in the period of collapse. The strong 1983 year-class, which contributed most significantly to 
Observed vs. predicted age at maturation

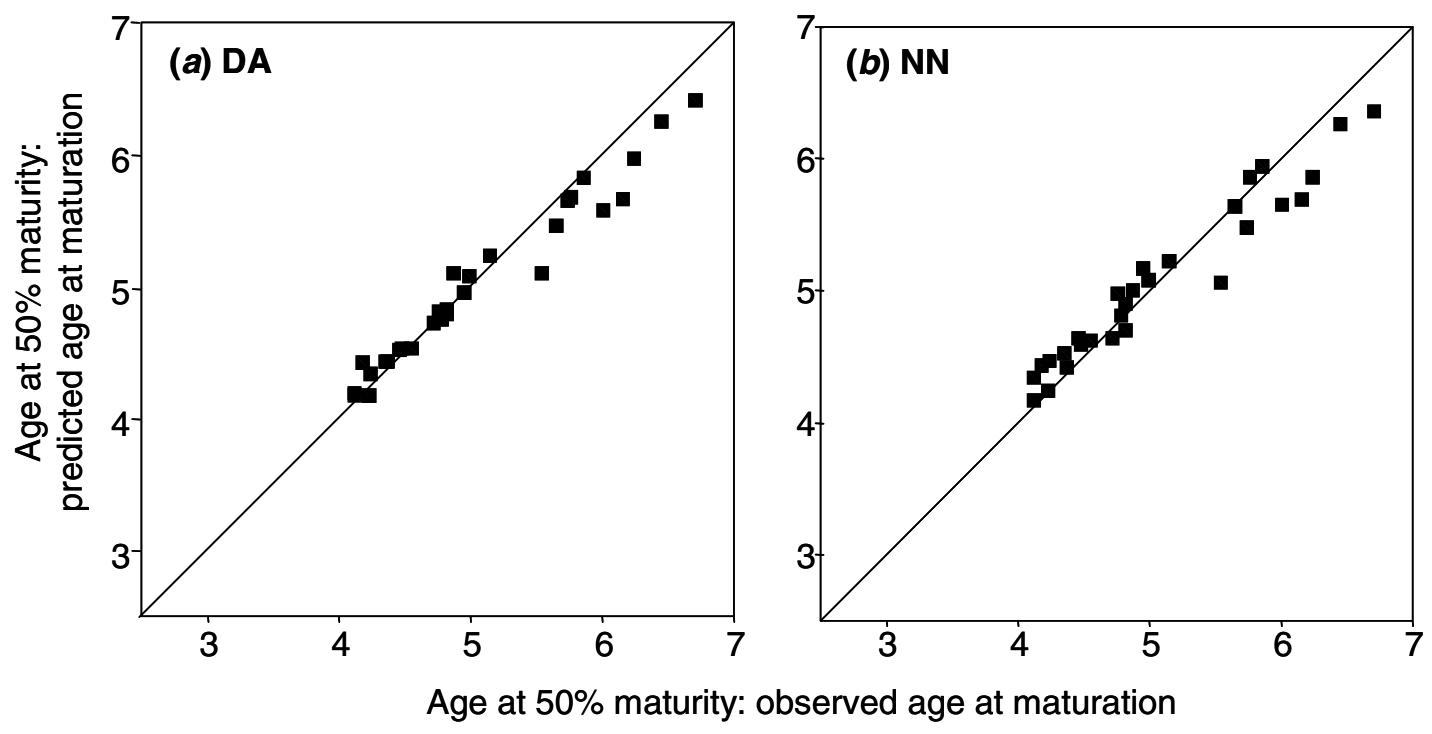

Gulland's vs. direct method

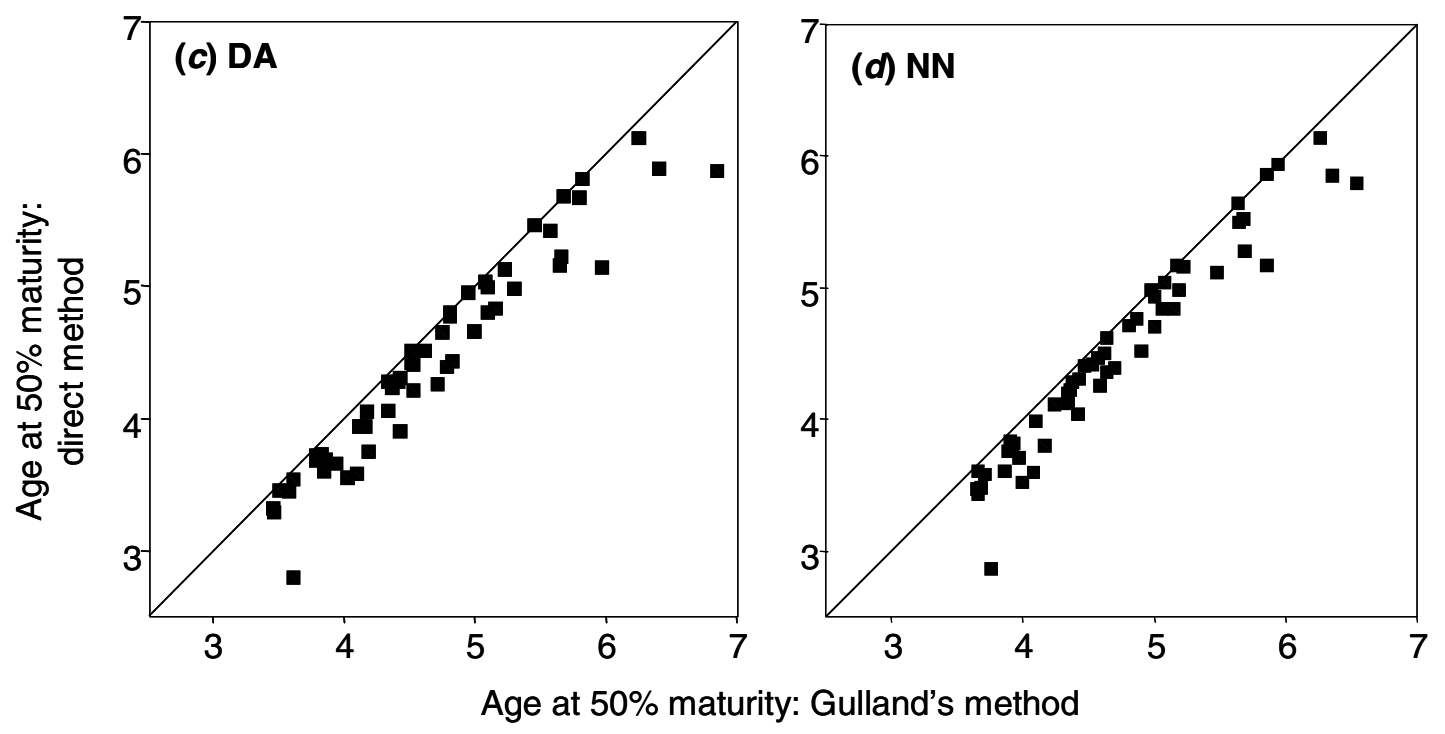

Figure $1 \boldsymbol{a}-\boldsymbol{d}$ : Comparisons of values of age at $50 \%$ maturity (A50) for year-classes as computed using different combinations of methods (see Methods section). Upper graphs: A50 results based on age at maturation observed by scale readers (data available only for year-classes 1930B1962) compared with A50 results based on age at maturation predicted using (a) discriminant analysis (DA) and (b) neural network analysis (NN), in combination with Gulland=s (1964) method. Lower graphs: A50 results based on Gulland's method and the "direct" method compared, if age at maturation is predicted using (c) DA and $(d)$ NN. Note close correspondence between results obtained with DA and NN, but generally higher values obtained with Gulland's than with the direct method. 

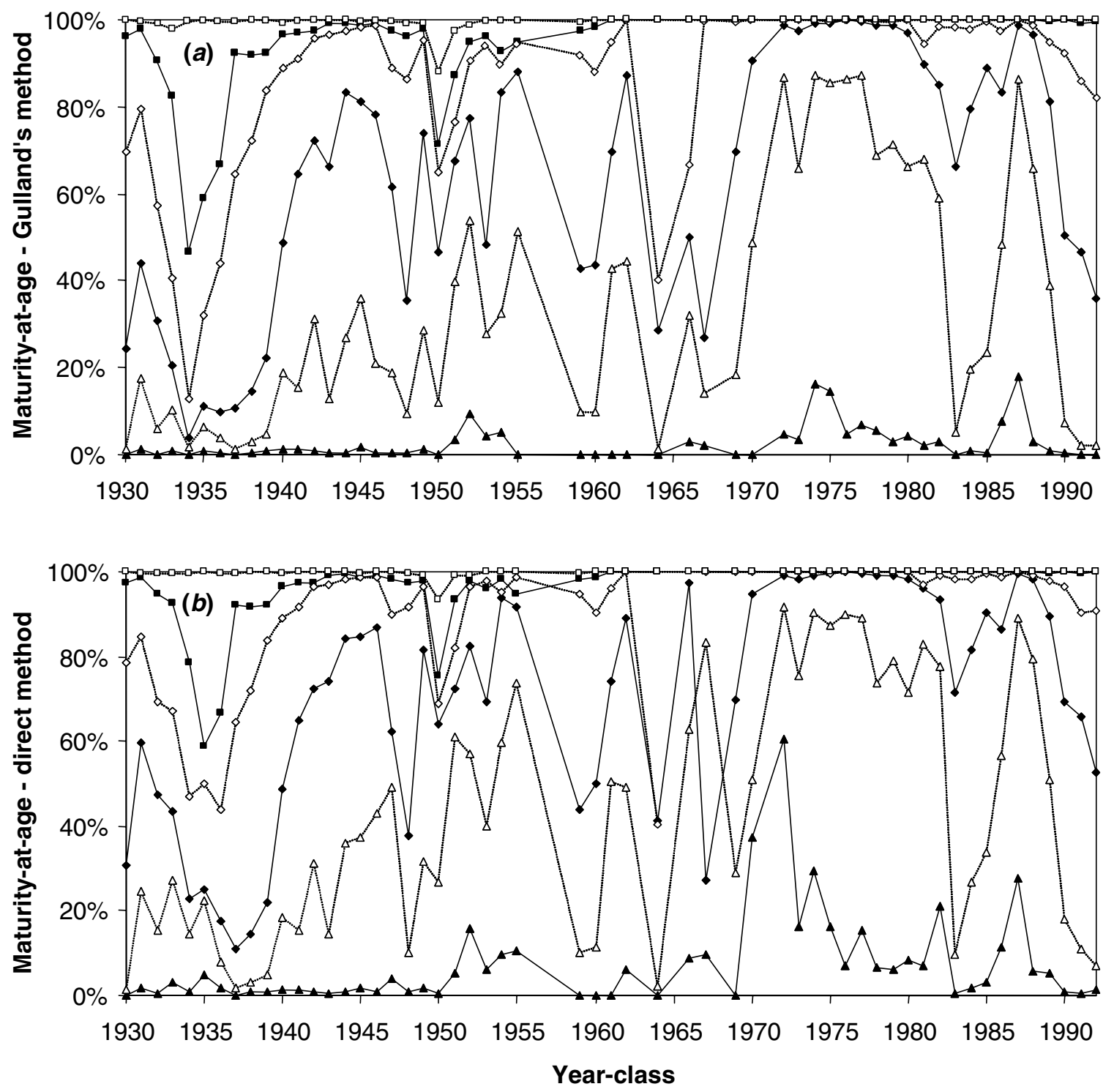

\begin{tabular}{|c|c|c|}
\hline$\multimap$ Age 3 & $\longrightarrow$ Age 5 & - Age 7 \\
\hline$\triangle \quad$ Age 4 & $\because$ Age 6 & Age 8 \\
\hline
\end{tabular}

Figure $2 \boldsymbol{a}, \boldsymbol{b}$ : The proportions of individuals mature at ages 3 to 8 for the year-classes 1930-1992, as computed (a) using Gulland's (1964) method and (b) using the direct method. In both graphs, DA was used to predict age at maturation from scale measurements in individual fish. 
the stock's recovery, again showed slow maturation, and the majority of this year-class was mature only at the age of 5. Maturity-at-age in more recent year-classes has been variable, in some resembling the collapse period (1987 year-class in particular) and in others resembling the pre-collapse period $(1983,1991$, and 1992 year-classes in particular).

Fig. $3 a$ shows the time-series of the age at 50\% maturity (A50) for year-classes from 1930 to 1992, as computed using Gulland's and the direct method. Although the values computed using Gulland's method are generally higher than those computed using the direct method (see above), the results show the same decreasing trend from the 1930s (about 5 or 6 years) to the period of stock collapse (about 4 years), and in the post-collapse period rather irregular but again generally higher A50 values. An analysis of variance (Table 1) shows that A50 values, computed using various methods, are significantly different between year-classes representing the periods before, during and after the collapse $(P<0.0001)$. Post-hoc comparisons show that while values were lowest in the collapse period, present values are still significantly lower than those of the pre-collapse period (Table 1).

For the years 1950-1995, A50 values computed from previously published maturity-atage data (ICES, 2002) are shown in Fig. 4, together with A50 values for the years 1935-1995 based on the ogives of this paper. There was a reasonable agreement in the long-term patterns in A50 values based on both ogives, and values were significantly correlated $(r=0.382, n=$ $46, P=0.009)$. Although A50 values computed using the direct method lay frequently below those computed from published ogives, there was no significant difference between values computed by either method (paired $t$-test, $t=1.22, P=0.229$ ).

\subsection{Trends in maturity-at-length}

The time-series on the length at 50\% maturity (L50) mirrors that of the age at 50\% maturity (Fig. 3b). It shows that the year-classes 1969-1982 representing the period of stock collapse, on average matured at higher lengths $(\sim 30 \mathrm{~cm})$ than earlier or later year-classes did $(\sim 29 \mathrm{~cm})$. Although the overall differences between year-classes in L50 were relatively small $(\mathrm{few} \mathrm{cm})$, there were nevertheless significant differences in L50 values between year-classes before, during and after the collapse period (Table 1: $P<0.0001$ ). Current values are intermediate between those of the collapse and pre-collapse periods.

\subsection{Trends in length-at-age}

Year-classes from the 1930s to the 1970s showed a generally increasing trend in the mean length at ages 1-6 (Fig. 5), with year-to-year fluctuations; for instance, the length-at-age was low in several year-classes of the late 1950s and early 1960s. The length-at-age was significantly higher during the collapse period (year-classes 1967-1982) than during the preand post-collapse periods (Table 1). This difference in growth between periods was already noticeable at age 1, but was most pronounced at ages 2 and 3; at ages 4-6 the difference was less marked but still significant. In the post-collapse period, the length-at-age was low in some year-classes $(1983,1991$, and 1992 year-classes in particular), while it was high in others (1987 year-class in particular). Overall, length-at-age during the post-collapse period was intermediate between that in the collapse and pre-collapse periods (Table 1). 

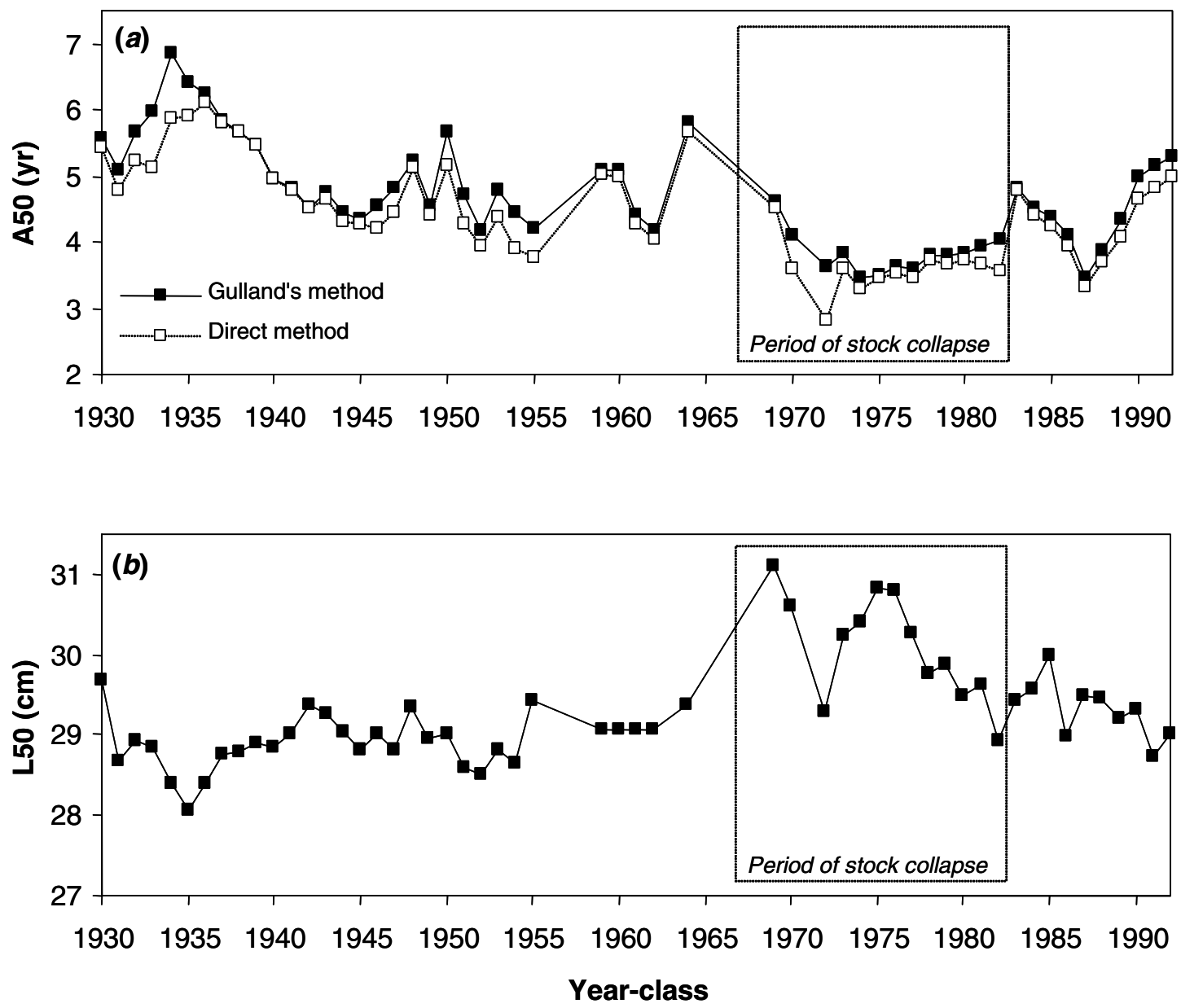

Figure $3 a$ : Time-series on age at 50\% maturity (A50) for the year-classes 1930-1992, as derived from ogives computed with either Gulland's or the "direct" method. - Figure $3 \mathbf{b}$ : Time-series on length at $50 \%$ maturity (L50) for the same year-classes. In both graphs, DA was used to predict age at maturation from scale measurements in individual fish.

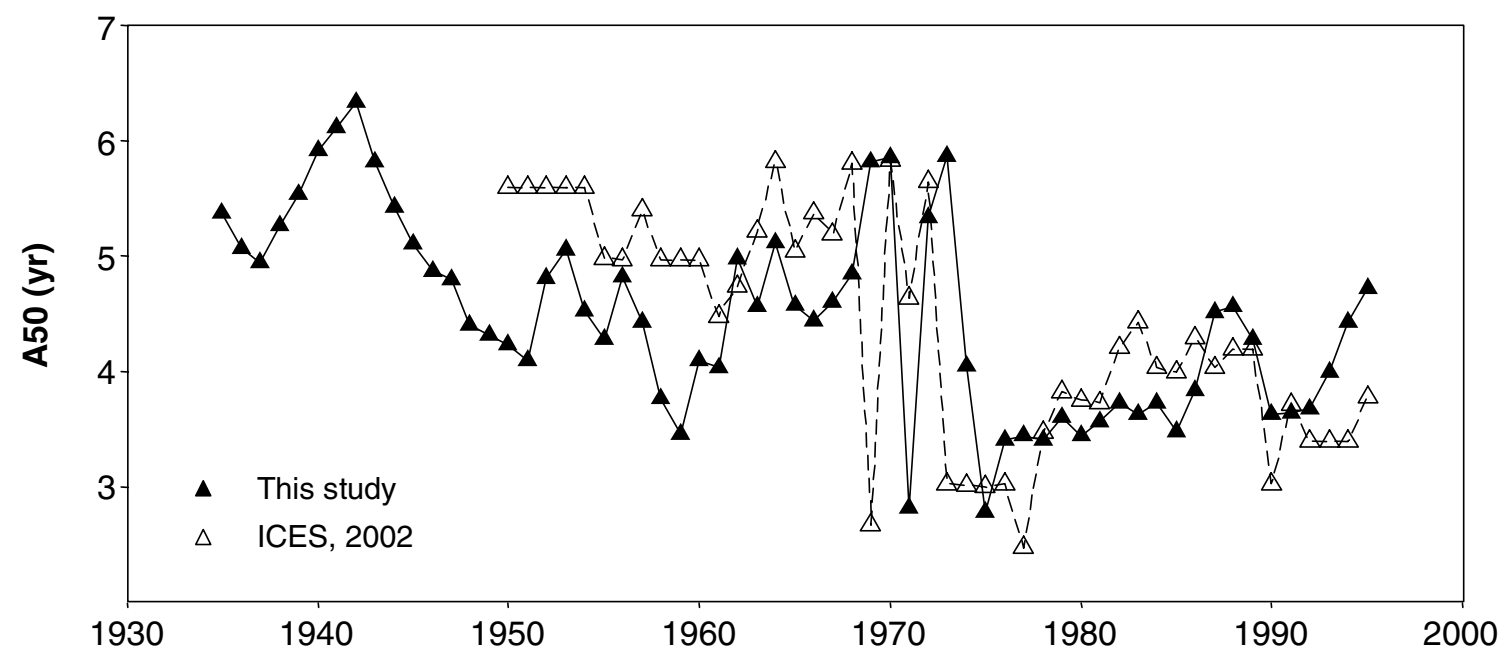

Figure 4: Time-series on age at 50\% maturity (A50), as computed based on previously published maturity-atage data (unfilled symbols, for the years 1950-1995; from ICES, 2002); and time-series as computed using the direct method and based on predictions of age at maturation made using DA (filled symbols, for the years 19351995). Note that results are shown per year of catch, and not per year-class. 
Table 1: Maturation and growth characteristics (means $\forall$ SD; based on values computed per year-class) in periods before, during, and after the collapse of the Norwegian spring-spawning herring stock. Values of A50 and L50 are computed based on predictions of age at maturation using DA. Analysis of variance (ANOVA) tests for overall differences in maturation characteristics between the three periods. Post-hoc comparisons (with Bonferroni adjustment) test for differences between pairs of periods ( $b, d$ and $a$ refer to periods before, during and after the collapse, respectively; symbols $<$ and $>$ refer to directions of differences significant at $P=0.05$ level; symbol $\sim$ refers to absence of a significant difference).

\begin{tabular}{lccccc}
\hline & $\begin{array}{c}\text { Before } \\
n=31\end{array}$ & $\begin{array}{c}\text { During } \\
n=13\end{array}$ & $\begin{array}{c}\text { After } \\
n=10\end{array}$ & $\begin{array}{c}\text { ANOVA } \\
P\end{array}$ & $\begin{array}{c}\text { Post-hoc } \\
\text { comparisons }\end{array}$ \\
\hline Year-classes & $1930-1966$ & $1967-1982$ & $1983-92$ & & \\
A50 (yr): Gulland's method & $5.10 \pm 0.71$ & $3.83 \pm 0.31$ & $4.49 \pm 0.59$ & $<0.0001$ & $b>d, d<a, b>a$ \\
A50 (yr): direct method & $4.86 \pm 0.66$ & $3.58 \pm 0.37$ & $4.29 \pm 0.54$ & $<0.0001$ & $b>d, d<a, b>a$
\end{tabular}

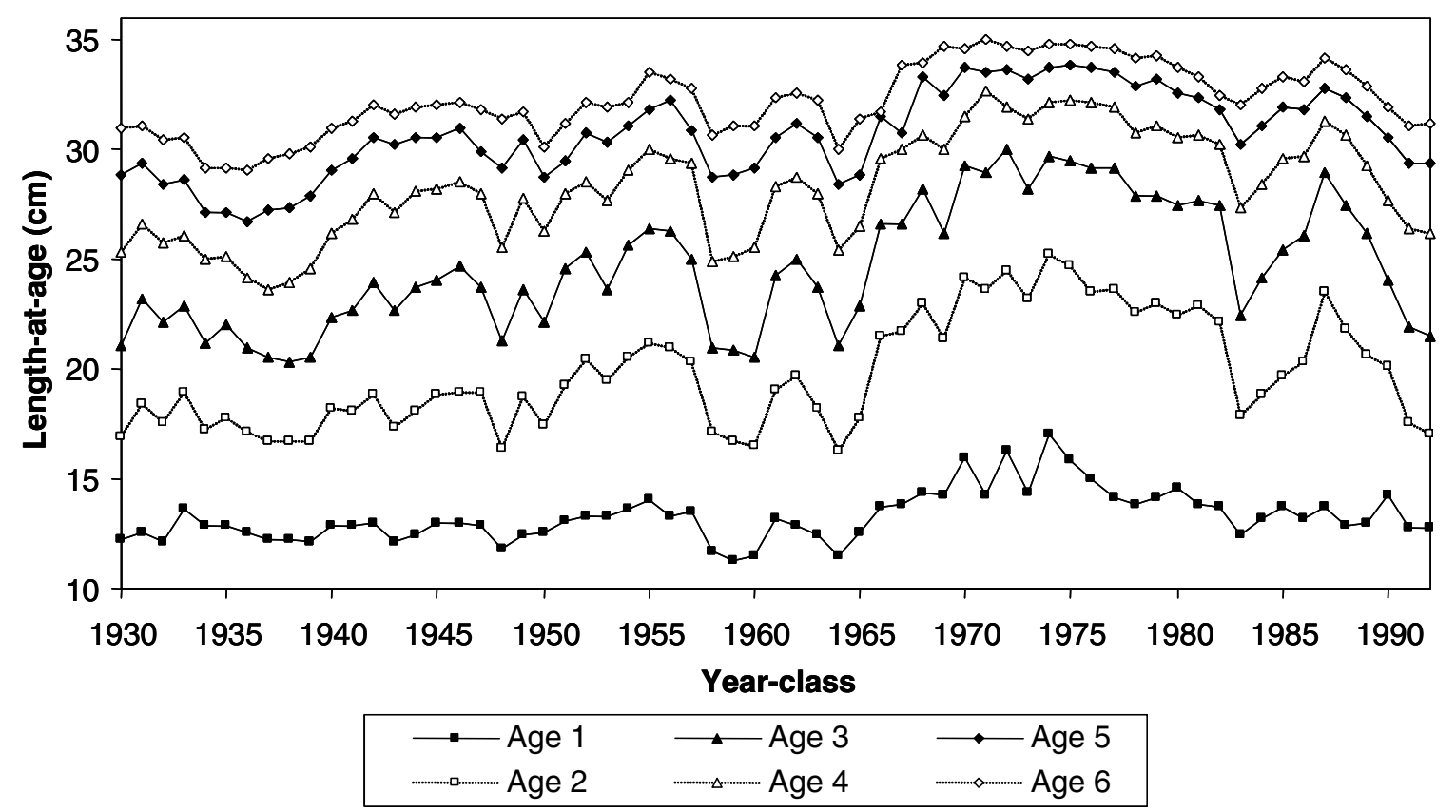

Figure 5: The mean length at ages 1-6 for the year-classes 1930-1992. 


\section{Discussion}

This is the first paper, to our knowledge, to show maturity ogives for Norwegian springspawning herring with a temporal resolution of 1 year encompassing periods well before, during, and after the stock collapse. In the light of the relatively limited information already available, the values presented here serve to the understanding and description of changes in stock properties that may have occurred since, or have resulted from, the collapse.

There are wide differences in the spatial distribution of early immature, late immature, and mature individuals of Norwegian spring-spawning herring in the Norwegian Sea and Barents Sea (Devold, 1963; Dragesund et al., 1980, 1997). Due to this spatio-temporal segregation it is difficult to establish maturity ogives directly based on the sampling of immature and mature fish, as observed proportions are unlikely to reflect the true proportions in the population. It is possible, however, to establish maturity ogives based solely on information of adult individuals using Gulland's (1964) method or the "direct" method. These methods require age at maturation to be known. Such knowledge has now become available with the application of discriminant and neural network analysis to classify age at maturation based on routine measurements of growth layers in herring scales (Engelhard et al. 2003).

Maturity ogives published previously for this stock are based on different methods than those used in this paper. The methods used to derive the ogives used in the assessment of Norwegian spring-spawning herring (Toresen and Østvedt, 2000; ICES, 2002) are unfortunately not well documented, but are probably based on maturity in the overwintering areas. However, these ogives have lower temporal resolution than ours. Moreover, ogives that have a temporal resolution of 1 year but are limited to year-classes before the collapse (i.e. 1928-1964 year-classes) have recently been published (Toresen and Østvedt, 2002). These ogives were calculated with a method akin to our direct method, but based solely on herring captured at age 9 where age at maturation had been directly observed from the scale by scale readers. The maturity ogives obtained with each of these methods differ in details, but fortunately, are in agreement at broader level.

The unbiased estimation of maturity ogives is contingent on the assumptions of the estimation methods being fulfilled. In particular, the methods applied here assume that survival of immature or mature herring at a given age are similar. This assumption is likely to have been violated in the study population for most of the time. The most important commercial fishery on this stock has traditionally occurred at the spawning areas, targeting the adult component. There have in addition been periods during which fisheries on juvenile herring took place (so-called small herring and fat herring fisheries, before 1971). However, these mainly targeted very young fish of ages 0-3 years, below ages most relevant for maturation (Dragesund and Ulltang, 1978). This implies that at ages relevant here (with a possible exception at age 3 in some periods), mature fish probably typically suffered greater mortality than immatures, violating the assumptions required for both Gulland's (1964) method and the "direct" method (see Methods) as used here to compute the maturity ogives. However, we expect the resulting biases in the ogives to be in opposite directions, and therefore the "true" ogives to be intermediate between those presented here.

The key result of this study is the demonstration of important changes in maturation and growth characteristics in Norwegian spring-spawning herring, both between periods before and during stock collapse (cf. Toresen, 1990a, b) and in the post-collapse period. During the collapse period when the abundance was very low, the herring matured at unusually early 
ages (in particular at ages 3-4 rather than 5-7); the age at 50\% maturity was considerably lower and the length at 50\% maturity somewhat higher than previously. The study confirms the increase in length-at-age when the stock was at low levels, as discussed by Toresen (1990a). It shows that, in addition, growth and maturation characteristics in the current, postrecovery period are intermediate between those of the collapse and pre-collapse periods (see also Dragesund et al., 1997 on changes in biological properties in the stock). The most recent trend seen throughout the year-classes 1987-1992 suggests that these characteristics might be returning to those typical for the pre-collapse period; future analysis including the most recent year-classes (currently recruiting to the spawning stock) may either confirm or refute this tendency.

The most plausible causes for the observed changes in growth and maturation characteristics are ecological factors related to stock abundance. Because herring tend to mature at a fixed size, stock size-related variations in growth are probably the main factor underlying the fluctuations in maturation properties as reported here (Fig. 5). In general, growth of Norwegian spring-spawning herring is negatively affected by year-class strength, due to two mechanisms (Toresen, 1990a). First, juveniles of weak year-classes are typically restricted geographically to the temperate coastal waters and fjords of Norway, while those of strong year-classes are also distributed widely in the cold waters of the Barents Sea, leading to reduced growth. Second, growth in juvenile herring is density-dependent (Iles, 1967; Hubold, 1978; Holst, 1996; Shin and Rochet, 1998), and the density of herring in fjords is much higher when rich year-classes occur then for small year-classes (Toresen, 1990a). Analogously, the collapse of the stock to very low abundance levels must have caused a relaxation of density-dependent effects, with resultant higher growth rates. Moreover, in the period of collapse, the stock was virtually absent from the northern half of its former range (Dragesund et al., 1997; Holst and Slotte, 1998). Even though the collapse coincided with a period of generally lower temperatures (Toresen and Østvedt, 2000), this more southerly distribution implied warmer average conditions experienced by juveniles, and therefore faster growth rates and earlier maturation (Runnström 1936). Thus it appears that phenotypically plastic changes in growth can explain the maturity changes to a large extent.

An intriguing question, however, remains. Can the maturity changes be attributed to the full extent to variations in growth rates, as phenotypically plastic responses of the fish to changes in their biotic and physical environment? Or are these, in addition, due to changes in the genetic composition of the stock, resulting from the selection pressures caused by fisheries, in particular during the period of over-exploitation (cf. Law, 2000; Browman, 2000)? It has been shown for at least two other important, commercially exploited fish stocks that drastic decreases in age at maturation were only partly due to phenotypic plasticity in growth, and that fisheries-induced selection for early-maturing phenotypes has indeed taken place (i.e., Northeast Arctic cod: Heino et al. 2002; North Sea plaice: Grift et al. 2003). The next major challenge - for a more complete understanding of the maturity changes in the Norwegian spring-spawning herring stock - is the disentanglement of environmental influences on maturation (via phenotypic plasticity) and the potential fisheries-induced genetic change. 


\section{References}

Barot, S., Heino, M., O’Brien, L., Dieckmann, U., 2002. Reaction norms for age and size at maturation: study of the long-term trend (1970-1998) for Georges Bank and Gulf of Maine cod stocks. ICES C.M. 2002/Y:03.

Barros, P., Holst, J.C., 1995. Identification of geographic origin of Norwegian spring-spawning herring (Clupea harengus L.) based on measurements of scale annuli. ICES J. Mar. Sci. 52, 863-872.

Bernardo, J., 1993. Determinants of maturation in animals. Trends Ecol. Evol. 8, 166-173.

Browman, H.I., 2000. Application of evolutionary theory to fisheries science and stock assessment-management. Mar. Ecol. Prog. Ser. 208, 299.

Corten, A., 2001. Herring and climate: changes in the distribution of North Sea herring due to climatic conditions. Ph.D. Diss., Univ. Groningen, The Netherlands.

Devold, F., 1963. The life history of the Atlanto-Scandian herring. Rapp. P.-V. Réun. Cons. int. Explor. Mer 154, 98-108.

Dragesund, O., Ulltang, Ø., 1978. Stock size fluctuations and rate of exploitation of the Norwegian spring spawning herring, 1950-1974. FiskDir. Skr. Ser. HavUnders. 16, 315-337.

Dragesund, O., Hamre, J., and Ulltang, Ø., 1980. Biology and population dynamics of the Norwegian spring-spawning herring. Rapp. P.-V. Réun. Cons. int. Explor. Mer 177, 4371.

Dragesund, O., Johannesen, A., Ulltang, Ø., 1997. Variation in migration and abundance of Norwegian spring spawning herring (Clupea harengus L.). Sarsia 82, 97-105.

Engelhard, G.H., Dieckmann, U., Godø, O.R., 2003. Age at maturation predicted from routine scale measurements in Norwegian spring-spawning herring (Clupea harengus) using discriminant and neural network analyses. ICES J. Mar. Sci. 60, 304-313.

Francis, R.I.C.C., 1990. Back-calculation of fish length: a critical review. J. Fish Biol. 36, 883-902.

Godø, O.R., 2000. Maturation dynamics of Arcto-Norwegian cod. Interim Rep. IR-00-024, IIASA, Laxenburg, Austria.

Grift, R.E., Rijnsdorp, A.D., Barot, S., Heino, M., Dieckmann, U., 2003. Fisheries-induced trends in reaction norms for maturation in North Sea plaice. Mar. Ecol. Prog. Ser. 257, 247-257.

Gulland, J.A., 1964. The abundance of fish stocks in the Barents Sea. Rapp. P.-V. Réun. Cons. int. Explor. Mer 155, 126-137.

Hamre, J., 1990. Life history and exploitation of the Norwegian spring spawning herring. In: Monstad, T., (Ed.), Biology and Fisheries of the Norwegian Spring Spawning Herring and Blue Whiting in the Northeast Atlantic. Institute of Marine Research, Bergen, Norway, pp. 5-39.

Heino, M., Dieckmann, U., Godø, O.R., 2002. Reaction norm analysis of fisheries-induced adaptive change and the case of the Northeast Arctic cod. ICES C.M. 2002/Y:14.

Heino, M., Godø, O.R., 2002. Fisheries-induced selection pressures in the context of sustainable fisheries. Bull. Mar. Sci. 70, 639-656.

Hile, R., 1941. Age and growth of the rock bass, Ambloplites rupestris (Rafinesque), in Neblish Lake, Wisconsin. Trans. Wis. Acad. Sci. Arts Lett. 33, 189-337.

Hjort, J., 1914. Fluctuations in the great fisheries of Northern Europe viewed in the light of biological research. Rapp. P.-V. Réun. Cons. int. Explor. Mer 20, 1-228. 
Holst, J.C., 1996. Long term trends in the growth and recruitment pattern of the Norwegian spring-spawning herring (Clupea harengus Linnaeus 1758). Ph.D. Diss., Univ. Bergen, Norway.

Holst, J.C., Slotte, A., 1998. Effects of juvenile nursery on geographic spawning distribution in Norwegian spring-spawning herring (Clupea harengus L.). ICES J. Mar. Sci. 55, 987-996.

Hubold, H., 1978. Variations in growth rate and maturity of herring in the northern North Sea in the years 1955-1973. Rapp. P.-V. Réun. Cons. int. Explor. Mer 172, 154-163.

ICES, 2002. Report of the Northern Pelagic and Blue Whiting Fisheries Working Group, Vigo, Spain, 29 AprilB8 May 2002. ICES C.M. 2002/ACFM:19.

Iles, T.D., 1967. Growth studies on North Sea herring. I. The second year=s growth (I-group) of East Anglian herring. 1939-63. J. Cons. Int. Explor. Mer 31, 56-76.

Jørgensen, T., 1990. Long-term changes in age at sexual maturity of Northeast Arctic cod (Gadus morhua L.). J. Cons. Int. Explor. Mer 46, 235-248.

Law, R., 2000. Fishing, selection, and phenotypic evolution. ICES J. Mar. Sci. 57, 659-668.

Law, R., Grey, D.R., 1989. Evolution of yields from populations with age-specific cropping. Evol. Ecol. 3, 343-359.

Lea, E., 1928. Undersøkelser over den norske sild: fra umoden til moden. Årsb. vedk. Norges Fisk. 1927 (IV), 1-36.

Lea, E., 1929. The oceanic stage in the life history of the Norwegian herring. J. Cons. 4, 1-42.

Marshall, C.T., Kjesbu, O.S., Yaragina, N.A., Solemdal, P., Ulltang, Ø., 1998. Is spawner biomass a sensitive measure of the reproductive and recruitment potential of Notheast Arctic cod? Can. J. Fish. Aquat. Sci. 55, 1766-1783.

Murawski, S.A., Rago, P.J., Trippel, E.A., 2001. Impacts of demographic variation in spawning characteristics on reference points for fishery management. ICES J. Mar. Sci. $58,1002-1014$.

Rijnsdorp, A.D., 1993. Fisheries as a large-scale experiment on life-history evolution: disentangling phenotypic and genetic effects in changes at maturation and reproduction of North Sea plaice, Pleuronectes platessa L. Oecologia 96, 391-401.

Rumelhart, D.E., Hinton, G.E., Williams, R.J., 1986. Learning representations by backpropagating errors. Nature 323, 533-536.

Runnström, S., 1936. A study on the life history and migrations of the Norwegian spring-herring based on the analysis of the winter rings and summer zones of the scale. FiskDir. Skr. Ser. HavUnders. 5 (2), 1-103.

Shin, Y.-J., Rochet, M.-J., 1998. A model for the phenotypic plasticity of North Sea herring growth in relation to trophic conditions. Aquat. Living Resour. 11, 315-324.

Stearns, S.C., 1992. The Evolution of Life Histories. Oxford University Press, New York.

Toresen, R., 1990a. Long-term changes in growth of Norwegian spring-spawning herring. J. Cons. int. Explor. Mer 47, 48-56.

Toresen, R., 1990b. Long-term changes of growth and maturation in the Norwegian spring spawning herring. In: Monstad, T., (Ed.), Biology and Fisheries of the Norwegian Spring Spawning Herring and Blue Whiting in the Northeast Atlantic. Institute of Marine Research, Bergen, Norway, pp. 89-106.

Toresen, R., 2002. Environmental influences on herring (Clupea harengus L.) abundance: an environmental approach for the understanding of herring stock fluctuations and its application in management. Ph.D. Diss., Univ. Bergen, Norway. 
Toresen, R., Østvedt, O.J., 2000. Variation in abundance of Norwegian spring-spawning herring (Clupea harengus, Clupeidae) throughout the 20th century and the influence of climatic conditions. Fish Fish. 1, 231-256.

Toresen, R., Østvedt, O.J., 2002. Stock structure of Norwegian spring-spawning herring: historical background and recent apprehension. ICES Mar. Sci. Symp. 215, 532-542.

Trippel, E.A., 1995. Age at maturity as a stress indicator in fisheries. BioScience 45, 759771. 